Guest Editorial, part of a Special Feature on Sustaining Ecosystem Services in Cultural Landscapes: Analysis and Management Options

\title{
Sustaining ecosystem services in cultural landscapes
}

\author{
Tobias Plieninger $^{1,2}$, Dan van der Horst $^{3}$, Christian Schleyer ${ }^{4}$ and Claudia Bieling $^{5}$
}

\begin{abstract}
Classical conservation approaches focus on the man-made degradation of ecosystems and tend to neglect the socialecological values that human land uses have imprinted on many environments. Throughout the world, ingenious land-use practices have generated unique cultural landscapes, but these are under pressure from agricultural intensification, land abandonment, and urbanization. In recent years, the cultural landscapes concept has been broadly adopted in science, policy, and management. The interest in both outstanding and vernacular landscapes finds expression in the UNESCO World Heritage Convention, the European Landscape Convention, and the IUCN Protected Landscape Approach. These policies promote the protection, management, planning, and governance of cultural landscapes. The ecosystem services approach is a powerful framework to guide such efforts, but has rarely been applied in landscape research and management. With this paper, we introduce a special feature that aims to enhance the theoretical, empirical and practical knowledge of how to safeguard the resilience of ecosystem services in cultural landscapes. It concludes (1) that the usefulness of the ecosystem services approach to the analysis and management of cultural landscapes should be reviewed more critically; (2) that conventional ecosystem services assessment needs to be complemented by socio-cultural valuation; (3) that cultural landscapes are inherently changing, so that a dynamic view on ecosystem services and a focus on drivers of landscape change are needed; and (4) that managing landscapes for ecosystem services provision may benefit from a social-ecological resilience perspective.
\end{abstract}

Key Words: cultural landscapes; driving forces; ecosystem services; landscape management; socio-cultural valuation

\section{INTRODUCTION}

"Cultural landscapes are at the interface between nature and culture, tangible and intangible heritage, biological and cultural diversity - they represent a closely woven net of relationships, the essence of culture and people's identity. Cultural landscapes are a focus of protected areas in a larger ecosystem context, and they are a symbol of the growing recognition of the fundamental links between local communities and their heritage, humankind and its natural environment." (Rössler 2006:334)

"The major grand challenges facing our society are embedded in landscape: climate change, energy needs, health and safety, food security, urbanisation and migration." (ESF 2010:1)

Until recently much of the research on global land-use change was focused on 'wild' lands and the shifting agricultural frontier, reporting trends such as deforestation, desertification, disappearance of wetlands, or burning of peatland (Foley et al. 2005, Green et al. 2005). However, in the 'postwild' world that we live in today (Marris 2011), there is a need to pay equal, or maybe even more, attention to the many cultural landscapes of the world that have been shaped by human agency over centuries. In many parts of the world, we experience that the demand for food, feed, and fiber is complemented by rising appreciation of the regulating and cultural services of landscapes (Martín-López et al. 2012). Landscapes today are also valued as everyday living environments, countryside, heritage, scenery with aesthetic and recreational qualities, and for their biodiversity values. For example, exurban migration and the global tourism boom are expressions of a soaring consumption of the aesthetic amenities of landscapes (Ferranto et al. 2011, Plieninger et al. 2012 for examples from the US). This special feature draws attention to the fate of cultural landscapes, seeking to engage with generic processes of change by adopting and adapting an ecosystem services approach that is sensitive to local context.
Cultural landscapes are undergoing rapid and fundamental transformations across the world, mainly as a result of an ongoing polarization of land use, with abandonment and rural exodus on the one hand, and intensification and (peri-) urbanization on the other. These processes are driven by changes in institutional arrangements, demography, policies, economic conditions, technologies, and climate. They have often resulted in the gradual replacement of traditional landscape practices by more standardized and mechanized land uses and are frequently accompanied by social and ecological tensions (cf. van der Horst and Evans 2010 for the case of energy landscapes). Although the specific drivers and outcomes of these processes vary from landscape to landscape, a central tendency is the fundamental decoupling of the socio-cultural and ecological subsystems in cultural landscapes (Matthews and Selman 2006). This leads to the degradation of biodiversity and cultural heritage values and renders the future of many of these landscapes highly uncertain. Both 'special' landscapes of high ecological or social value and ordinary 'everyday' landscapes are affected by these processes.

Today, we are facing an unprecedented competition for land (Smith et al. 2010). In addition to the growing demand for quality and status foods by expanding middle classes in rapidly developing countries, growth in world population also necessitates a quantitative increase in food production (Tilman et al. 2011). What will 'sustainable agricultural intensification' mean for those rural areas in which cultural landscape consumption has already overtaken agriculture in economic and political importance? What will it mean for developing countries in which the majority of the rural population is still living off the land, but in which traditional methods, knowledge, and institutions may no longer suffice? How can the diverse goods and services that different landscapes and ecosystems provide to human well-being be sustained under such conditions?

${ }^{1}$ University of Copenhagen, ${ }^{2}$ Humboldt-Universität zu Berlin, ${ }^{3}$ University of Edinburgh, ${ }^{4}$ Helmholtz Centre for Environmental Research - UFZ,

${ }^{5}$ University of Freiburg 
The protection and management of cultural landscapes have attracted broad attention from scientists, policy makers, and the general public (Conrad et al. 2011) because of the visibility, for instance, caused by the acknowledgement of cultural landscapes in the UNESCO World Heritage Convention (Rössler 2006). Over the past years, several initiatives have called for integrated landscape approaches to the management of natural resources. For example, the global Landscapes for People, Food, and Nature Initiative, co-organized by the United Nations Environment Programme, the United Nations Food and Agriculture Organisation, and other international organizations, seeks to address rural landscape management that integrates food production, biodiversity and ecosystem conservation, and rural livelihoods within supportive institutional and policy contexts (Milder et al. 2014). The Satoyama Initiative, launched at the Tenth Meeting of the Conference of the Parties (COP10) to the Convention on Biological Diversity in 2010, aims at fostering the management and sustainable use of biodiversity and ecosystem services in human-influenced landscapes, mainly through broader global recognition of the social-ecological values of these environments (Takeuchi 2010). The Protected Landscape Approach of the International Union for Conservation of Nature (IUCN), introduced in 2003, encompasses large-scale landscape mosaics from cultivated to wild lands that have been shaped and influenced by human interaction over time and acknowledges the critical links between nature, culture, and community for longterm sustainability of conservation (Brown et al. 2005). All these initiatives intend to preserve the regional diversity and heritage of cultural landscapes and, at the same time, seek to identify pathways to a more sustainable future.

Over the past years, the 'ecosystem services' approach, which aims to identify and valorize the multiple benefits that ecosystems provide to human well-being, has developed into a mainstream conservation paradigm. Besides exploitable 'direct' services, such as the provision of food or timber, ecosystems provide further goods and services, which are typically not duly perceived, recognized, or compensated by society (MEA 2005). The growing popularity of the ecosystem services approach has led to the worldwide emergence of initiatives and organizations aimed at the preservation of ecosystem functioning, among others via the introduction of market-based instruments (cf. Schleyer and Plieninger 2011 for an example from Germany). Although the ecosystem services framework is a potentially powerful guide for landscape research and management, it has rarely been applied in this realm (Schaich et al. 2010).

This special feature aims to enhance the theoretical, empirical, and practical knowledge of how to safeguard the resilience of ecosystem services in cultural landscapes. It contains 13 research papers, 1 synthesis paper, and 1 book review, assimilating perspectives from social-ecological systems studies, landscape ecology, conservation biology, spatial planning, human geography, political ecology, and other research fields. The contributions cover African, Asian, European, North American, and Latin American landscapes. When we look beyond differences in location and disciplinary perspective, we find crosscutting research challenges: (1) integrating cultural landscapes into the ecosystem services framework, (2) analyzing ecosystem services provided by cultural landscapes, (3) assessing drivers and impacts of landscape change, and (4) managing landscapes for the resilient provision of ecosystem services.

\section{INTEGRATING LANDSCAPE INTO THE ECOSYSTEM SERVICES FRAMEWORK}

Some of the existing literature, especially that which was written in the early years of the Millennium Ecosystem Assessment, presents a simplistic picture of ecosystem services as being produced by nature and consumed by humans. Several authors challenge this notion head-on, providing through their assessment of cultural landscapes the evidence that such a dichotomy of supply and demand does no justice to the complex and dynamic characteristics of human-nature relations. For example, Gu and Subramanian (2014) and Huntsinger and Oviedo (2014) examine ecosystem services in cultural landscapes as social-ecological systems. Gu and Subramanian take us through the origins of the Satoyama Initiative and the emergence of the concept of socio-ecological production landscapes (SEPL), which they illustrate across a wide range of different production systems. Huntsinger and Oviedo's work is very different in that it is deeply anchored in a specific case study on California's Mediterranean Rangelands. However, many of their arguments and insights will be recognizable to those of us who work in different empirical settings. Huntsinger and Oviedo use a multiscale approach, comprising pasture, range, and landscape scales, to demonstrate that notwithstanding historic frictions and mistrust, the farmer and the conservationist have many common interests and concerns; indeed the farm's continued profitability and the resilience of the ecosystem are fully codependent. Vallés et al. (2014) and Villamagna and Giesecke (2014) are interested in questions of identification and classification with regard to ecosystem services in concrete landscapes. Vallés et al. embrace the term landscape for its particular suitability to express the contextual interdependence and inherent inseparability of humans and nature. Grounded in a detailed review of existing ecosystem services classifications, they develop a new 'landscape services' classification to suit the needs of collaborative landscape planning that is sensitive to locally defined cultural services. Villamagna and Giesecke's contribution is not just to unpack 'nature's contribution to human well-being,' but also to actually map it in a particular geographical setting. Although they acknowledge the methodological and conceptual challenges involved, their approach is both pragmatic and innovative, combining objective criteria from the literature with the local values and preferences elicited through stakeholder engagement.

\section{ANALYZING ECOSYSTEM SERVICES AT LANDSCAPE SCALE}

Given the complex interplay of a multitude of features, processes, benefits, and values that is characteristic of cultural landscapes, landscape-scale analysis of ecosystem services is a particular challenge. One way to address this challenge is through the sociocultural valuation of ecosystem services. López-Santiago et al. (2014) present a valuation approach, which explores the social perceptions of ecosystem services connected to landscapes that have been shaped by seasonal livestock migrations (transhumance) in Spain. Using photographs as visual stimuli in questionnaires, they elicited 16 ecosystem services and showed that ecosystem services valuation can turn out quite different for contrasting landscape types and respondent groups. They revealed conflicts and trade-offs in ecosystem services appreciation and derived insights for land management and policy making. The authors argue that the socio-cultural dimension of ecosystem services assessment is particularly relevant in cultural 
landscapes because it acknowledges the broad multifunctionality of landscapes, provides information about the perceptions of local people rather than experts, and draws attention to the consequences of changing land uses. Taking a slightly different socio-cultural perspective, Hartel et al. (2014) provide another survey-based approach for analyzing ecosystem services from a socio-cultural perspective. They assessed ecosystem services in a cultural landscape with rich heritage values in Central Romania, which is rapidly changing in social and economic terms. Based on a survey across 30 villages, they found provisioning ecosystem services to be particularly valued by local inhabitants. Connecting these findings with interviews on past, present, and possible future changes, they concluded that reliance on local ecosystem services is increasingly being lost, although new, meaningful ways to keep the social and ecological landscape components connected still remain to be developed. Barbedo et al. (2014) introduce a modeling approach that can be useful in analyzing directional ecosystem service flows in landscapes and their effects on the wellbeing of people. They argue that some ecosystem services, such as the ability of landscapes to mitigate floods, are undervalued because they are not seen or experienced by the person who damages them. To make these relationships visible, the authors employ a hydrodynamic model that quantifies the downstream impacts of potential land-use changes in upstream areas, like higher construction density, which may have an impact on the flood alleviation capacity of a landscape in the Brazilian coastal city of Paraty.

\section{ASSESSING DRIVERS AND IMPACTS OF LANDSCAPE CHANGE}

Changes in cultural landscapes and in the ecosystem services they provide are determined by a plethora of often interrelated driving forces, such as changes in technology, societal preferences for specific ecosystem services, policies, and biophysical conditions. Identifying relevant drivers and linking them to concrete impacts on landscapes is crucial to understand landscape dynamics and constitutes a significant methodological challenge. Drawing on a variety of case studies from Asia and other countries worldwide, $\mathrm{Gu}$ and Subramanian (2014) investigated major drivers of landscape change. Their synthesis is deliberately multidimensional and demonstrates the need for the critical examination of economic, cultural, political, and social trends, in addition to a strong understanding of the natural processes affecting the landscape. Specifically, they showed that socio-political transformations, such as the process of nation-state building as well as changes in legal rights, e.g., property rights on natural resources, and the level of territorial autonomy of indigenous communities have had tremendous impacts on many landscapes. Similarly powerful are the processes of (global) market integration and trade liberalization, but also demographic and socio-cultural changes, such as the challenge to preserve traditional, ecological, and other knowledge. Using the example of a German biosphere reserve, Ohnesorge et al. (2013) defined and assessed concrete land cover change processes in different zones within the protected area and in a surrounding reference area by analyzing digital biotope maps. Although the biosphere reserve as a whole seems to be more effective in realizing specific land cover related management goals since its designation in 1994, they unexpectedly found, however, that some highly desirable key processes of land cover change, such as the conversion of coniferous plantations into seminatural forests, have been more extensive outside the reserve. Van der Horst and Vermeylen (2014) highlighted biofuels as large-scale drivers of landscape change. Specifically, they focused on the close relationship between the level of production of hedges composed of Jatropha curcas and their ability to provide ecosystem services. Drawing on a local case study in the eastern province of Zambia, they showed that predominantly using jathropha hedges for supply of provisioning services, such as biofuels, would require expanding the production up to landscape capacity. This, however, would be at odds with many other ecosystem services, such as the cultural and regulating ecosystem services, e.g., using the hedges to fence agricultural plots, which are highly valued and demanded by local farming villages. As Plieninger et al. (2013) illustrate, local actors are an important source for identifying key drivers of landscape change, for assessing possible future impacts on ecosystem services, and for exploring local management strategies. In two municipalities in southern Germany, the authors facilitated the participatory development of stakeholder-based scenarios for local landscape and ecosystem services developments taking into account variations in global-level drivers, such as more or less state regulation and support, and in local-level forces, such as more or less appreciation of the local cultural landscape by tourists.

\section{MANAGING LANDSCAPES FOR THE RESILIENT PROVISION OF ECOSYSTEM SERVICES}

How can cultural landscapes be managed for the resilient provision of ecosystem services? Synthesizing the resilience literature, Plieninger and Bieling (2013) identified eight critical social-ecological system properties and components. On the basis of landscape-scale case studies, they explore how these features may be integrated in the management of agricultural European landscapes that are of high nature value but under pressure from socioeconomic changes. Kizos et al. (2014) deepen the issue of landscapes and social-ecological resilience in a case study on land degradation in a semiarid mountain area of Crete/Greece. In particular, they addressed the role of social capital among livestock farmers and other local actors, which has undergone substantial transformations from the 1950s until today. The case study by Zimmerer (2014) on the Tarata-Arbieto landscape in the central Andes of Bolivia is centered on agrobiodiversity, which is an important component of landscape resilience and a provider of multiple ecosystem services. Studying the impacts of migration and livelihood diversification processes, which are prevalent throughout Latin America, the study identified management and policy options for the in situ conservation of local, foodproducing crop types (landraces) by involving multiple migrantrelated groups and their social networks. Ango et al. (2014) take this issue further by examining an agricultural-forest mosaic landscape in southwestern Ethiopia. From a smallholder farmer perspective, the authors assessed the provision of ecosystem services and disservices provided by farm trees and nearby forests to agricultural production and local livelihoods. They point to the importance of a balanced and differentiated view on the services and disservices that different species and types of farm trees and woodlands provide.

\section{CONCLUSIONS}

The contributions to this special feature give a rich description of the values, but also of the strong changes that many of the world's 
cultural landscapes are undergoing. The papers have assumed an ecosystem services perspective, but they also showed that the potentials and limitations of the ecosystem services approach to the analysis and management of cultural landscapes should be reviewed more critically. Much of the research also points out that conventional ecosystem services assessment, whether biophysical modeling or monetary valuation, needs to be complemented by socio-cultural approaches to acknowledge the diverging perspectives and land-use conflicts. Moreover, it stresses that cultural landscapes are inherently changing, so that a dynamic view on ecosystem services and a focus on drivers of landscape change are needed. Finally, it acknowledges that managing landscapes for ecosystem services provision may benefit from a social-ecological resilience perspective. This special feature emphasizes the fact that cultural landscapes are still living landscapes; it is neither feasible nor is it good for society to 'freeze' them. Some changes cannot be stopped, and some changes come with new values or correspond to particular needs. Most importantly, we argue that cultural landscapes illustrate that conservation and development need not always be stark opposites; in fact society can find ways for them to go hand in hand.

Responses to this article can be read online at: http://www.ecologyandsociety.org/issues/responses. $\mathrm{php} / 6159$

\section{Acknowledgments:}

Both Tobias Plieninger's and Claudia Bieling's contributions have received funding from the European Community's Seventh Framework Programme under Grant Agreement No. 603447 ( Project HERCULES).

\section{LITERATURE CITED}

Ango, T.-G., L. Börjeson, F. Senbeta, and K. Hylander. 2014. Balancing ecosystem services and disservices: smallholder farmers' use and management of forest and trees in an agricultural landscape in southwestern Ethiopia. Ecology and Society 19(1): 30. http://dx.doi.org/10.5751/ES-06279-190130

Barbedo, J., M. Miguez, D. van der Horst, and M. Marins. 2014. Enhancing ecosystem services for flood mitigation: a conservation strategy for peri-urban landscapes? Ecology and Society 19(2): 54. http://dx.doi.org/10.5751/ES-06482-190254

Brown, J., N. Mitchell, and M. Beresford. 2005. Protected landscapes: a conservation approach that links nature, culture and community. Pages 3-18 in J. Brown, N. Mitchell, and M. Beresford, editors. The protected landscape approach: linking nature, culture and community. International Union for Conservation of Nature, Gland, Switzerland. [online] URL: http://data.iucn.org/dbtwwpd/edocs/2005-006.pdf

Conrad, E., M. Christie, and I. Fazey. 2011. Is research keeping up with changes in landscape policy? A review of the literature. Journal of Environmental Management 92:2097-2108. http://dx. doi.org/10.1016/j.jenvman.2011.04.003
European Science Foundation (ESF). 2010. Landscape in a changing world. Bridging divides, integrating disciplines, serving society. Science policy briefing 41. European Science Foundation, Strasbourg, Germany.

Ferranto, S., L. Huntsinger, C. Getz, G. M. Nakamura, W. C. Stewart, S. L. Drill, Y. Valachovic, M. DeLasaux, and M. Kelly. 2011. Forest and rangeland owners value land for natural amenities and as financial investment. California Agriculture 65:184-191. http://dx.doi.org/10.3733/ca.v065n04p184

Foley, J. A., R. DeFries, G. P. Asner, C. Barford, G. Bonan, S. R. Carpenter, F. S. Chapin, M. T. Coe, G. C. Daily, H. K. Gibbs, J. H. Helkowski, T. Holloway, E. A. Howard, C. J. Kucharik, C. Monfreda, J. A. Patz, I. C. Prentice, N. Ramankutty, and P. K. Snyder. 2005. Global consequences of land use. Science 309:570-574. http://dx.doi.org/10.1126/science.1111772

Green, R. E., S. J. Cornell, J. P. W. Scharlemann, and A. Balmford. 2005. Farming and the fate of wild nature. Science 307:550-555. http://dx.doi.org/10.1126/science.1106049

Gu, H., and S. Subramanian. 2014. Drivers of change in socioecological production landscapes: implications for better management. Ecology and Society 19(4): 41. http://dx.doi. org/10.5751/ES-06283-190141

Hartel, T., J. Fischer, C. Campianu, A. Milcu, J. Hanspach, and I. Fazey. 2014. The importance of ecosystem services for rural inhabitants in a changing cultural landscape in Romania. Ecology and Society 19(2): 42. http://dx.doi.org/10.5751/ES-06333-190242

Huntsinger, L., and J. Oviedo. 2014. Ecosystem services are socialecological services in a traditional pastoral system: the case in California Mediterranean rangelands. Ecology and Society 19(1): 8. http://dx.doi.org/10.5751/ES-06143-190108

Kizos, T., V. Detsis, T. Iosifides, and M. Metaxakis. 2014. Social capital and social-ecological resilience in the Asteroussia Mountains, southern Crete, Greece. Ecology and Society 19(1): 40. http://dx.doi.org/10.5751/ES-06208-190140

López-Santiago, C., E. Oteros-Rozas, B. Martín-López, T. Plieninger, E. González, and J. A. González. 2014. Using visual stimuli to explore the social perceptions of ecosystem services in cultural landscapes: the case of transhumance in Mediterranean Spain. Ecology and Society 19(2): 27. http://dx.doi.org/10.5751/ ES-06401-190227

Marris, E. 2011. Rambunctious garden: saving nature in a post-wild world. Bloomsbury, New York, New York, USA.

Martín-López, B., I. Iniesta-Arandia, M. García-Llorente, I. Palomo, I. Casado-Arzuaga, D. García Del Amo, E. GómezBaggethun, E. Oteros-Rozas, I. Palacios-Agundez, B. Willaarts, J. A. González, F. Santos-Martín, M. Onaindia, C. LópezSantiago, and C. Montes. 2012. Uncovering ecosystem service bundles through social preferences. PloS ONE 7:e38970. http:// dx.doi.org/10.1371/journal.pone.0038970

Matthews, R., and P. Selman. 2006. Landscape as a focus for integrating human and environmental processes. Journal of Agricultural Economics 57:199-212. http://dx.doi.org/10.1111/ j.1477-9552.2006.00047.x 
Milder, J. C., A. K. Hart, P. Dobie, J. Minai, and C. Zaleski. 2014. Integrated landscape initiatives for African agriculture, development, and conservation: a region-wide assessment. World Development 54:68-80. http://dx.doi.org/10.1016/j.worlddev.2013.07.006

Millennium Ecosystem Assessment (MEA). 2005. Ecosystems and human well-being: synthesis. Island, Washington, D.C., USA. [online] URL: http://www.unep.org/maweb/documents/document.356. aspx.pdf

Ohnesorge, B., T. Plieninger, and P. Hostert. 2013. Management effectiveness and land cover change in dynamic cultural landscapes - assessing a Central European biosphere reserve. Ecology and Society 18(4): 23. http://dx.doi.org/10.5751/ ES-05888-180423

Plieninger, T., and C. Bieling. 2013. Resilience-based perspectives to guiding high-nature-value farmland through socioeconomic change. Ecology and Society 18(4): 20. http://dx.doi.org/10.5751/ ES-05877-180420

Plieninger, T., C. Bieling, B. Ohnesorge, H. Schaich, C. Schleyer, and F. Wolff. 2013. Exploring futures of ecosystem services in cultural landscapes through participatory scenario development in the Swabian Alb, Germany. Ecology and Society 18(3): 39. http://dx.doi.org/10.5751/ES-05802-180339

Plieninger, T., S. Ferranto, L. Huntsinger, M. Kelly, and C. Getz. 2012. Appreciation, use, and management of biodiversity and ecosystem services in California's working landscapes. Environmental Management 50:427-440. http://dx.doi.org/10.1007/ $\underline{\mathrm{S} 00267-012-9900-\mathrm{Z}}$

Rössler, M. 2006. World heritage cultural landscapes: A UNESCO flagship programme 1992-2006. Landscape Research 31:333-353. http://dx.doi.org/10.1080/01426390601004210

Schaich, H., C. Bieling, and T. Plieninger. 2010. Linking ecosystem services with cultural landscape research. GAIA 19:269-277. [online] URL: http://www.landespflege-freiburg.de/ ressourcen/schaich 2010 gaia.pdf

Schleyer, C., and T. Plieninger. 2011. Obstacles and options for the design and implementation of payment schemes for ecosystem services provided through farm trees in Saxony, Germany. Environmental Conservation 38:454-463. http://dx.doi.org/10.1017/ $\underline{\mathrm{S} 0376892911000361}$

Smith, P., P. J. Gregory, D. van Vuuren, M. Obersteiner, P. Havlik, M. Rounsevell, J. Woods, E. Stehfest, and J. Bellarby. 2010. Competition for land. Philosophical Transactions of the Royal Society B-Biological Sciences 365:2941-2957. http://dx.doi. org/10.1098/rstb.2010.0127

Takeuchi, K. 2010. Rebuilding the relationship between people and nature: the Satoyama initiative. Ecological Research 25:891-897. http://dx.doi.org/10.1007/s11284-010-0745-8

Tilman, D., C. Balzer, J. Hill, and B. L. Befort. 2011. Global food demand and the sustainable intensification of agriculture. Proceedings of the National Academy of Sciences 108:20260-20264. http://dx.doi.org/10.1073/pnas.1116437108
Vallés, M. C., F. Galiana, and V. Van Eetvelde. 2014. A classification of landscape services to support local landscape planning. Ecology and Society 19(1): 44. http://dx.doi. org/10.5751/ES-06251-190144

van der Horst, D., and J. Evans. 2010. Carbon claims and energy landscapes: exploring the political ecology of biomass. Landscape Research 35:173-193. http://dx.doi.org/10.1080/01426390903564879

van der Horst, D., and S. Vermeylen. 2014. The hedgification of maizescapes? Scalability and multifunctionality of Jatropha curcas hedges in a mixed farming landscape in Zambia. Ecology and Society19(2): 48. http://dx.doi.org/10.5751/ES-06437-190248

Villamagna, A., and C. Giesecke. 2014. Adapting human wellbeing frameworks for ecosystem service assessments across diverse landscapes. Ecology and Society 19(1): 11. http://dx.doi. org/10.5751/ES-06173-190111

Zimmerer, K. S. 2014. Conserving agrobiodiversity amid global change, migration, and nontraditional livelihood networks: the dynamic uses of cultural landscape knowledge.. Ecology and Society 19(2): 1. http://dx.doi.org/10.5751/ES-06316-190201 